\title{
Development of a Diet Quality Score for Infants and Toddlers and its Association with Weight
}

\author{
Elaine M Ríos ${ }^{1}$, Olga Sinigaglia ${ }^{1}$, Beatriz Diaz ${ }^{2}$, Maribel Campos $^{2}$, Cristina Palacios ${ }^{1}$ \\ ${ }^{1}$ Nutrition Program, School of Public Health, Medical Sciences Campus, University of Puerto Rico \\ ${ }^{2}$ Undergraduate Department, School of Nursing, Medical Sciences Campus, University of Puerto Rico
}

Received: August 25, 2016; Accepted: September 28, 2016; Published: October 18, 2016

*Corresponding author: Cristina Palacios, PhD, Nutrition Program, Department of Human Development, Graduate School of Public Health,Medical Sciences Campus, University of Puerto Rico, San Juan PR 00936-5067, Phone: (787) 758-2525 Ext. 1433; Fax: (787) 759-6719; Email: cristina.palacios@upr.edu

\begin{abstract}
Objective: To create a Diet Quality Index Score (DQIS) for infants and toddlers and to assess its relative validity.

Design: Three DQIS were created (0-5, 8-11 and 12-24 months) based on a validated food frequency questionnaire (FFQ). Nine components were included, scored from 0 (inadequate) to 5 (adequate consumption) based on guidelines for timing of food's introduction and portion sizes; the component on breastfeeding (Yes/No) was scored (0-15). Infants 6-7 months were excluded as new foods are introduced during this period. The total score (0-55 points) was categorized as Excellent $(\geq 45)$, Good (35-44), Needs improvement (25-34), and Poor ( $<25)$. Relative validity was assessed against weight status among a sample of 296 children using logistic regression.
\end{abstract}

Results: In infants 0-5 months ( $\mathrm{n}=100)$, mean DQIS was $42.4 \pm 9.3$ and $52 \%$ had 'Excellent' diets. In infants 8-11 months ( $\mathrm{n}=42)$, mean DQIS was $36.1 \pm 7.7$ and most had 'Good' diets (47.6\%). Among toddlers 12-24 months ( $\mathrm{n}=117)$, mean DQIS was $25.7 \pm 8.0$ and most had 'Poor' diets (50.4\%). There was a trend for a higher odd of Excessive weight in those with 'Poor' diets compared to those with 'Excellent' diets, after controlling for confounders (OR 2.01; 95\% CI: 0.85, 5.18).

Conclusions: These scores could be used to assess diet quality in infants and toddlers. There was a trend for a higher odd of Excessive weight among those with 'Poor' diets. To our knowledge, this is the first algorithm for the assessment of diet quality in infants and toddlers considering intake of each food group and their portion sizes.

Keywords: Diet Quality; Diet Score; Weight Status; Infants; Toddlers

\section{Introduction}

Adequate nutrition is essential for growth and development during the first years of life and for the prevention of future chronic diseases, such as obesity, diabetes, cancer, among others [1]. Currently, childhood obesity has become one of the most alarming concerns of public health in the US [2] and it is staring earlier in life, with $8.1 \%$ prevalence of excessive weight in infants and toddlers in 2011-2012 [3]. This high prevalence in such young group could be partially attributed to the early introduction of solids and altered feeding practices during these early years $[1,4,5]$, but more evidence is needed.

Assessing diet quality in the population is important as this allows monitoring compliance to dietary guidelines. However, this has not been properly studied in infants and toddlers. Although several studies have characterized dietary patterns in this group [6-9], there are only three diet quality scores developed specifically for infants and toddlers [10-12]. One score was developed to assess diet quality in infants 6 months and older in the United Kingdom (UK) based on adherence to complementary feeding guidelines [10]. The index was based on 14 components related to breast feeding, timing of introduction to solids, meal frequency and other feeding practices, but it did not take into consideration the amount of food consumed. Another score entitled Infant and Child Feeding Index was created for infants 6-23 months based on the World Health Organization (WHO) feeding guidelines [11]. This score consists of 5 components (breastfeeding, use of the bottle, food frequency, dietary diversity and frequency of feeding solids) but it also did not take into account portion sizes. The third score was created using data from the Raine Study, a longitudinal survey in Australian children [12]. This score included the frequency of consumption of 7 components (whole grains, vegetables, fruits, meat ratio, dairy, snack foods, soda, and drinks) and was based on a modified Healthy Eating Index for children. Although it takes into account portion sizes, it did not include breastfeeding and, to our knowledge, it has not been validated.

Developing a diet score for this age group is challenging for two main reasons: (1) there are many changes occurring in a short period of time as new foods and beverages are introduced and (2) the US Dietary Guidelines does not include children 0-24 months, which difficult the creation of the score, as this usually monitors compliance to published guidelines. However, there are a few dietary guidelines currently in use for this population, such as the guidelines by the Women, Infants, and Children Nutritional Supplementation Program (WIC) [13], the WHO [14] and the 
American Academy of Pediatrics [15]. Therefore, the aim of this study was to create a Diet Quality Index Score using the available guidelines and to assess its relative validity.

\section{Methods}

\section{Study Design}

This was a cross-sectional study to create a diet quality score in infants and toddlers 0-24 months of age. We recruited caregivers of infants and toddlers' participants of a WIC clinic in Puerto Rico. Caregivers completed a socio-demographic questionnaire and the Infant and Toddler Semi-Quantitative Food Frequency Questionnaire (FFQ). Also, weight and length were taken in the infants and toddlers. A signed consent and willingness to participate from the caregivers was obtained. This study was approved by the Institutional Review Board of the Medical Science Campus at the University of Puerto Rico.

\section{Participants}

We recruited a convenience sample of 296 caregivers of infants and toddlers aged 0-24 months. Recruitment occurred daily in the only WIC clinic in the Municipality of Trujillo Alto in Puerto Rico from November 2014 to February 2015. This allowed recruitment of all active WIC participants of that municipality. We excluded children with any serious health condition that could alter normal feeding practices.

\section{Socio-demographic questionnaire}

It included questions related to caregivers, such as age, gender, and educational attainment and questions on the infants and toddlers, such as age and gender.

\section{Anthropometric assessment}

Weight and length were assessed in children by trained research personnel. Caregivers were asked to remove diapers or put a clean diaper on the child and remove accessories such as hats, bonnets, coats, shoes, socks, bibs, etc. Weight was measured in pounds (later converted to $\mathrm{kg}$ ) using a manual scale (Detecto model 3p7044, Missouri), which was calibrated daily. Recumbent length was measured in $\mathrm{cm}$ using an infantometer (Perspective Enterprises model \#PE-RILB-BRG2, Michigan). Measurements were taken in duplicates and averaged. Weight status was assessed with weight-for-length using the WHO growth charts by age and sex [16]. Weight was categorized as Healthy $\left(<90^{\text {th }}\right.$ percentile) and Excessive ( $\geq 90^{\text {th }}$ percentile).

\section{Dietary Assessments}

An Infant and Toddler Semi-quantitative FFQ was used to characterize the child's food intake in the first two years of life. This FFQ includes 52 items with portion sizes and has been previously validated in a similar population [17]. A picture guide was created to aid caregivers estimate portion sizes of fruits, vegetables, milk, cereals, cookies, salted snacks, protein foods and beverages. It was completed during a face-to-face interview by trained personal.

\section{Diet Quality Index Score (DQIS)}

Three different scores were created to assess diet quality based on the Infant and Toddler semi-quantitative FFQ for the following age groups: 0-5 months, 8-11 months and 12-24 months. We excluded participants aged 6-7 months, as this is a period of introduction of solids and other beverages, with many changes occurring every week; therefore, it is difficult to assess dietary patterns in this group.

\section{DQIS for infants 0-5 months}

For this score, we included nine components: Milk (exclusive or partial breastfeeding or formula feeding), Grains or cereals, Proteins (meat or beans), Vegetables, Fruits, 100\% fruit juices, Sugar-sweetened beverages, Sweets, and Salty snacks. The scores were based only on timing of introduction of foods and beverages; for this, we considered the WIC's complementary feeding guidelines [13], the WHO feeding guidelines [14] and the recommendations of the American Academy of Pediatrics in the introduction of solids [15]. These guidelines recommend exclusive breastfeeding for infants 0-5 months, without any solid foods until 6 months (Table 1). For all the components, except for breastfeeding, a score of 5 was assigned if the food was not introduced and a score of 0 was assigned if the food was introduced. For breastfeeding, a score of 15 points was assigned if the infant was exclusively breastfed; a score of 10 points was assigned if partially breastfed (combination of breastfeeding and formula feeding); and a score of 5 points was assigned if the infant was only formula fed. We did not take into consideration the portion sizes of the food groups for this age group.

\begin{tabular}{|c|c|}
\hline Components & Scores $^{\mathrm{a}}$ \\
\hline Milk (type of feeding) & 15 (exclusive) \\
\hline Breastfeeding & 10 (partial) \\
\hline Formula feeding & 5 \\
\hline Cereal & $\begin{array}{c}\text { Not consumed }=5 \\
\text { Consumed }=0\end{array}$ \\
\hline Protein & $\begin{array}{c}\text { Not consumed }=5 \\
\text { Consumed }=0\end{array}$ \\
\hline Vegetables & $\begin{array}{c}\text { Not consumed }=5 \\
\text { Consumed }=0\end{array}$ \\
\hline Fruits & $\begin{array}{c}\text { Not consumed }=5 \\
\text { Consumed }=0\end{array}$ \\
\hline $100 \%$ fruit juices & $\begin{array}{c}\text { Not consumed }=5 \\
\text { Consumed }=0\end{array}$ \\
\hline Sugar-sweetened beverages & $\begin{array}{c}\text { Not consumed }=5 \\
\text { Consumed }=0\end{array}$ \\
\hline Sweets & $\begin{array}{c}\text { Not consumed }=5 \\
\text { Consumed }=0\end{array}$ \\
\hline Salty snacks & $\begin{array}{c}\text { Not consumed }=5 \\
\text { Consumed }=0\end{array}$ \\
\hline Total & $0-55$ \\
\hline
\end{tabular}

The scores were based on the age of introduction of these foods as recommended by the WIC's complementary feeding guidelines [13], the WHO feeding guidelines [14] and the American Academy of Pediatrics [15], not on portion sizes.

${ }^{\mathrm{b}}$ The score for Milk (Type of feeding) was based on YES/NO, without quantifying the amount of breast milk or formula. 


\section{DQIS for infants 8-11 months}

For this score, we included the same nine components. The scores were based on recommended portions following WIC's recommendations [13], the WHO feeding guidelines [14] and the Child and Adult Care Food Program Proposed Meal Pattern [18] (Table 2). We considered under and over consumption of each food group and the scores were as follows: 5 points if intake was within recommended amounts; 2.5 points if intake was slightly over or under the recommended amount; or 0 points if it was not consumed or intake was excessive. For the Milk group, two different scores were included. The first score assigned 10 points if the infant was breastfed (partially or exclusively) and 0 if the infant was not breastfed (the amount of breast milk was not taken into account). The second score took into consideration the amount of total milk consumed (formula, cow's milk, almond milk, and soy milk but not breast milk) and assigned 5 points if intake was within recommended amounts; 2.5 points if intake was slightly over or under the recommended amount; or 0 points if it was not consumed or intake was excessive.

\section{DQIS for infants 12-24 months}

For this score, we used a similar scoring system as for infants 8-11 months, but we adjusted the portion sizes using the same guidelines (Table 2).

\section{DQIS categorization}

The individual components scores were summed for each infant and toddler and a total score was obtained ranging from 0 to 55 points. The total score was categorized as:

Table 2: Diet Quality Index Score for infants and toddlers 8-24 months.

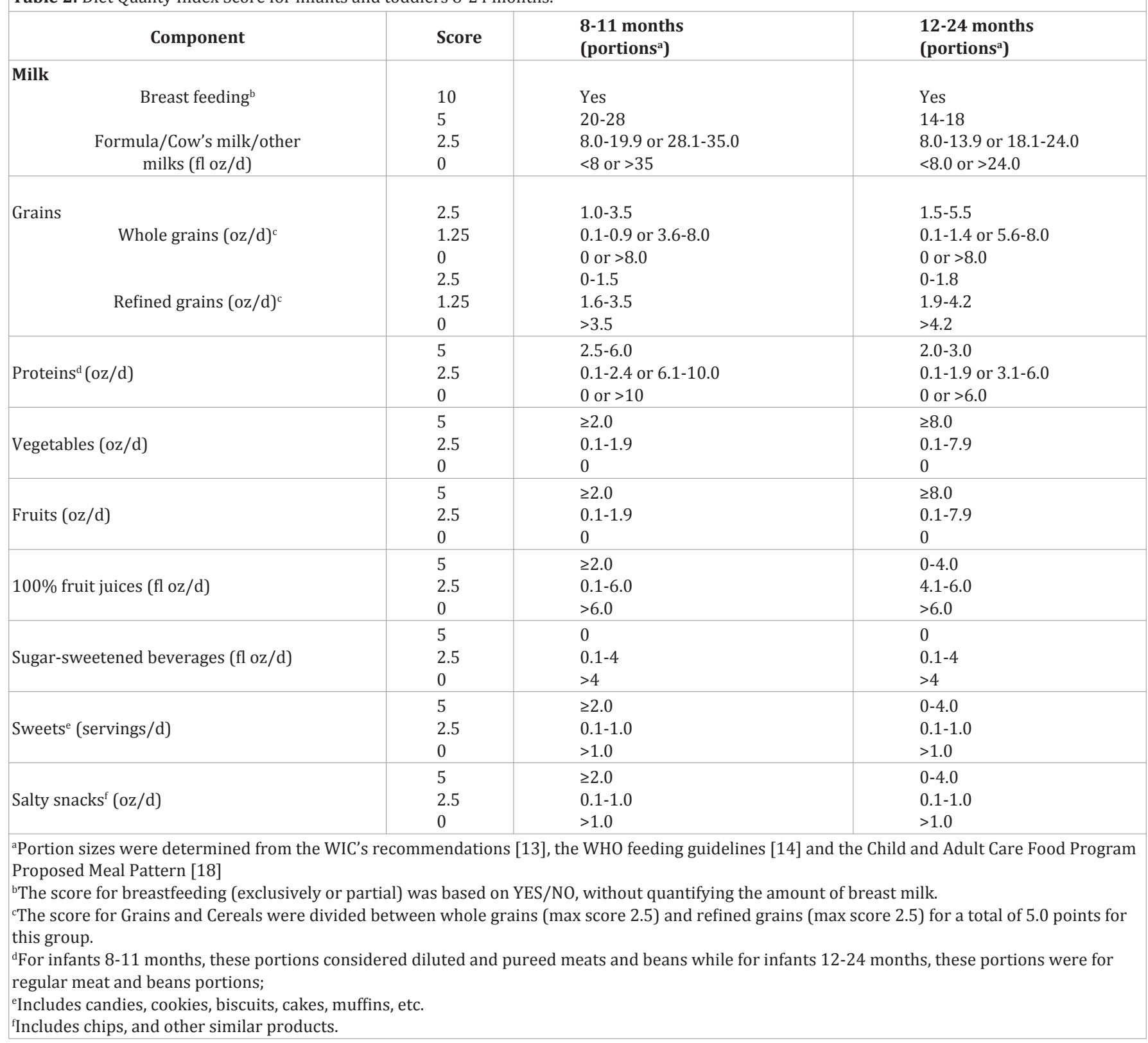


- Excellent, if the total score was $\geq 45$;

- Good, if the total score was 35-44;

- Needs improvement, if the total score was 25-34; and

- $\quad$ Poor, if the total score was $<25$.

\section{Statistical analysis}

For descriptive statistics, mean and standard deviations were computed for continuous variables and frequencies for categorical values. A binary logistic regression was conducted to examine the associations between weight status (Healthy versus Excessive weight) and the categorized DQIS. The model was adjusted for caregiver's age and education. All analyses were performed using SPSS Statistical Software (version 21.0 for Windows, 2012, Chicago, IL) and Excel (Microsoft, 2010). Statistical significance was set at $\mathrm{P}<0.05$.

\section{Results}

Table 3 shows the socio-demographic characteristics of the sample. A total of 296 participants were recruited. From these, four caregivers did not complete all the questionnaires, one child was not weighed and one child was older than 24 months. Also, infants aged 6-7 months $(n=31)$ were excluded, as described in Methods. Therefore, a total of 259 caregivers and their children

Table 3: General characteristics of caregivers and their infants/ toddlers $(\mathrm{n}=259)$

\begin{tabular}{|c|c|c|}
\hline \multicolumn{2}{|l|}{ Characteristics } & $\begin{array}{l}\text { Total sample } \\
\%(N) \text { or Mean (SD) }\end{array}$ \\
\hline \multicolumn{3}{|l|}{ Caregivers } \\
\hline Gender (female) & \multirow{5}{*}{$\begin{array}{l}\leq \text { High School } \\
>\text { High School }\end{array}$} & $98.8(256)$ \\
\hline Age (years) & & $28.3 \pm 6.7$ \\
\hline Education & & $40.6(105)$ \\
\hline & & $59.4(154)$ \\
\hline $\begin{array}{l}\text { Number of children } \\
\text { in household }\end{array}$ & & $1.9 \pm 1.0$ \\
\hline \multicolumn{3}{|l|}{ Infants/Toddlers } \\
\hline \multirow[t]{2}{*}{ Gender } & Female & 46.0 (119) \\
\hline & Male & $54.0(140)$ \\
\hline \multirow[t]{3}{*}{ Age } & 0-5 months & $38.6(100)$ \\
\hline & 8-11 months & $16.2(42)$ \\
\hline & $12-24$ months & $45.2(117)$ \\
\hline \multirow[t]{10}{*}{ Weight status $^{\mathrm{a}}$} & \multirow{4}{*}{$\begin{array}{l}\text { 0-5 months } \\
\text { Healthy weight } \\
\text { Excessive weight }\end{array}$} & \\
\hline & & \\
\hline & & $83.0(83)$ \\
\hline & & $17.0(17)$ \\
\hline & \multirow{3}{*}{$\begin{array}{l}\text { 8-11 months } \\
\text { Healthy weight } \\
\text { Excessive weight }\end{array}$} & \\
\hline & & $85.7(36)$ \\
\hline & & $14.3(6)$ \\
\hline & 12-24 months & \\
\hline & Healthy weight & $74.4(87)$ \\
\hline & Excessive weight & $25.6(30)$ \\
\hline
\end{tabular}

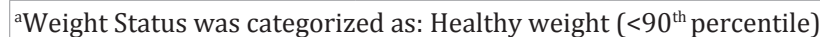
and Excessive weight as $\geq 90^{\text {th }}$ percentile.

\begin{tabular}{|c|c|c|c|c|c|c|}
\hline \multirow[b]{3}{*}{ Component } & \multicolumn{6}{|c|}{ Diet quality index score } \\
\hline & \multicolumn{2}{|c|}{$\begin{array}{l}\text { 0-5months } \\
(\mathrm{n}=100)\end{array}$} & \multicolumn{2}{|c|}{$\begin{array}{l}\text { 8-11months } \\
(\mathrm{n}=42)\end{array}$} & \multicolumn{2}{|c|}{$\begin{array}{l}\text { 12-24 months } \\
(\mathrm{n}=117)\end{array}$} \\
\hline & $\begin{array}{l}\text { Max } \\
\text { Score }\end{array}$ & $\begin{array}{l}\text { Mean } \pm \\
\text { SD }\end{array}$ & $\begin{array}{l}\text { Max } \\
\text { Score }\end{array}$ & $\begin{array}{l}\text { Mean } \pm \\
\text { SD }\end{array}$ & \begin{tabular}{|l|} 
Max \\
Score
\end{tabular} & $\begin{array}{l}\text { Mean } \pm \\
\text { SD }\end{array}$ \\
\hline $\begin{array}{l}\text { Breastfeeding (Yes/ } \\
\text { No) }\end{array}$ & 15 & $5.9 \pm 5.8$ & 10 & $4.3 \pm 5.0$ & 10 & $2.4 \pm 4.3$ \\
\hline $\begin{array}{l}\text { Any milk (breast, } \\
\text { formula, cow, others) } \\
\text { (fl oz/d) }\end{array}$ & & - & 5 & $2.8 \pm 1.8$ & 5 & $4.3 \pm 1.7$ \\
\hline $\begin{array}{l}\text { Grains or cereals } \\
(\mathrm{oz} / \mathrm{d})\end{array}$ & 5 & $5.0 \pm 0.0$ & & & & - \\
\hline Whole grains (oz/d) & & - & 2.5 & $1.2 \pm 0.9$ & 2.5 & $1.2 \pm 0.8$ \\
\hline Refined grains (oz/d) & & - & 2.5 & $1.1 \pm 1.1$ & 2.5 & $0.4 \pm 0.7$ \\
\hline Proteins (oz/d) & 5 & $5.0 \pm 0.0$ & 5 & $2.5 \pm 1.8$ & 5 & $1.3 \pm 1.7$ \\
\hline Vegetables (oz/d) & 5 & $5.0 \pm 0.0$ & 5 & $3.8 \pm 1.6$ & 5 & $3.9 \pm 1.3$ \\
\hline Fruits (oz/d) & 5 & $5.0 \pm 0.0$ & 5 & $4.5 \pm 1.2$ & 5 & $4.0 \pm 1.5$ \\
\hline 100\% Juices (fl oz/d) & 5 & $5.0 \pm 0.0$ & 5 & $2.5 \pm 1.7$ & 5 & $1.9 \pm 2.3$ \\
\hline $\begin{array}{l}\text { Sugar-sweetened } \\
\text { beverages (fl oz/d) }\end{array}$ & 5 & $5.0 \pm 0.0$ & 5 & $4.8 \pm 0.9$ & 5 & $2.3 \pm 1.7$ \\
\hline Sweets (servings/d) & 5 & $5.0 \pm 0.0$ & 5 & $3.9 \pm 1.5$ & 5 & $1.8 \pm 1.6$ \\
\hline Salty snacks (oz/d) & 5 & $5.0 \pm 0.0$ & 5 & $4.8 \pm 0.7$ & 5 & $3.9 \pm 1.3$ \\
\hline TOTAL & 55 & $\begin{array}{l}42.4 \pm \\
9.3\end{array}$ & 55 & $\begin{array}{l}36.1 \pm \\
7.7\end{array}$ & 55 & $\begin{array}{l}25.7 \pm \\
8.0\end{array}$ \\
\hline
\end{tabular}

Table 5: Association between Diet Quality Index Score and overweight ${ }^{1}$

\begin{tabular}{|l|l|l|l|l|}
\hline $\begin{array}{c}\text { Diet Quality Index } \\
\text { Score }\end{array}$ & OR & \multicolumn{1}{|c|}{$\mathbf{9 5 \%}$ CI } & $\begin{array}{c}\text { Adjusted } \\
\mathbf{O R}^{2}\end{array}$ & $\mathbf{9 5 \%} \mathbf{C I}$ \\
\hline Poor & 2.01 & $\begin{array}{l}(0.82, \\
4.95)\end{array}$ & 2.01 & $(0.85,5.18)$ \\
\hline Needs improvement & 0.84 & $\begin{array}{l}(0.30, \\
2.34)\end{array}$ & 0.83 & $(0.30,2.34)$ \\
\hline Good & 1.63 & $\begin{array}{l}(0.67, \\
3.97)\end{array}$ & 1.61 & $(0.66,3.95)$ \\
\hline Excellent & 1 & 1 & \\
\hline $\begin{array}{l}{ }^{1} \text { Healthy weight was used as the reference. } \\
\text { 2Adjusted for caregiver's age and education }\end{array}$ \\
\hline
\end{tabular}

(0-5 months $\mathrm{n}=100 ; 8-11$ months $\mathrm{n}=42 ; 12-24$ months $\mathrm{n}=117$ ) were included in the analysis. Most caregivers were females $(98.8 \%)$ and had a level of education higher than high school $(59.4 \%)$. A total of $54 \%$ of infants were male and $45 \%$ were aged $12-24$ months. In general, excessive weight was found in $20.5 \%$ of the sample, with a higher prevalence among toddlers aged 12 24 months $(25.6 \%)$.

The mean DQIS in infants 0-5 months was $42.4 \pm 9.3$ out of a total of 55 points (Table 4). Most were categorized as having 'Excellent' diets (52.0\%), followed by 'Good' diet (36.0\%), diets that 'Need improvement' (8.0\%) and 'Poor' $\operatorname{diet}(4.0 \%)$. The mean DQIS in infants 8-11 months was $36.1 \pm 7.7$ out of a total of 55 points (Table 4). Most were categorized as having 'Good' diets (47.6\%), followed by diets that 'Need improvement' (35.7\%), 'Excellent' diets (14.3\%) and 'Poor' diets (2.4\%). The lowest scores were for Breastfeeding, $100 \%$ fruit juices, and Proteins. The low scores for $100 \%$ fruitjuices and Proteins were due to their overconsumption. 
In particular, $26 \%$ of participants reported consuming $\geq 6$ fluid ounces of $100 \%$ fruit juices (recommended amount for this age group is 0 ounces) and $24 \%$ participants reported consuming $\geq 6$ ounces of foods from the protein group (recommended amount for this age group is 2.5 to 6.0 ounces). The mean DQIS in infants $12-24$ months was $25.7 \pm 8.0$ out of a total of 55 points (Table 4). Most were categorized as having 'Poor' diets (50.4\%), followed by diets that 'Need improvement' (32.5\%), 'Good' diets (16.2\%) and 'Excellent' diets (0.9\%). The lowest scores were for the following components: Milk, Proteins, Refined grains and $100 \%$ fruit juices; this was also due to overconsumption of these groups. In particular, we noted that $72 \%$ of infants consumed more than 18 ounces of milk (recommended amount for this age group is 14 to 18 ounces), with an average consumption of 26 ounces per day. Also, $81 \%$ of infants consumed more than 3 ounces of proteins (recommended amount for this age group is 2 to 3 ounces), with an average consumption of 8.7 ounces per day, which is more than double of the recommended amount. In addition, $68 \%$ consumed more than 4 ounces of $100 \%$ fruit juices (recommended amount for this age group is up to 4 ounces per day), with an average consumption of 8.4 ounces per day, which is double of the recommended amount.

In terms of relative validity, we found a trend between DQIS categories and weight status, in which those categorized as having 'Poor' diets had two-fold higher odds of Excessive weight compared to those categorized as having 'Excellent' diets, after controlling for caregiver's age and education (OR 2.01; 95\% CI: $0.85,5.18$ ).

\section{Discussion}

In the present study we designed a DQIS following the available guidelines for timing of introduction of solids for infants $0-5$ months and the guidelines for the recommended portion sizes of different food groups for infants 8-24 months $[13-15,18]$. There was a trend in the association of the DQIS with weight status, with a two-fold increase in Excessive weight among infants and toddlers with 'Poor' diets compared to those with 'Excellent' diets.

To our knowledge, this is the first attempt to create and validate a diet quality score for infants and toddlers considering the intake of each food group and their portion sizes (for infants 8-24 months). As mentioned earlier, a few other scores have been created to assess diet quality in both infants and toddlers. Two of the available scores do not take into account portion sizes [10, 11] the third score includes portion sizes but did not take into account breastfeeding and has not been validated [12]. Therefore, this study is filling a gap for a score that is based on the amount of food consumed while also taking into account type of feeding practices. In addition, as feeding practices change considerably during this period, we created three different scores.

In infants 0-5 months, the score basically assessed breastfeeding and timing of introduction of solids. Our results showed that the score was very high, with most infants categorized as having 'Excellent' or 'Good' diets (88\%). This indicates that most caregivers are compliant with the guidelines on age of introduction of complementary feeding and with the recommendation to breastfeed their infants.

Most infants 8-11 months also had 'Good' or 'Excellent' diets $(61.9 \%)$, indicating that most were compliant with the different feeding guidelines. Similar results were seen in the score created in the UK for infants 6 months and older, where the score reflected adherence to complementary guidelines [10]. In our sample, one of the components with the lowest scores was $100 \%$ fruit juices. This item is actually not recommended for this age group, so we assigned a score of 5 if consumption was 0 and a score of 0 is consumption was above 6 ounces per day. The consumption of $100 \%$ fruit juices has been traditionally perceived by parents as healthy, as these contain vitamins and minerals $[19,20]$. In fact, the food industry has developed juices specifically for babies, with jars that can be adjusted using the infant bottle's nipple. However, these beverages also contain high amounts of sugar, contributing to excessive sugar intake in the US [21]. In the case of proteins, the low scores in our study were due to overconsumption. The fact that our score was able to take into account overconsumption enabled us to detect and quantify this issue. Recommendations to address overconsumption of foods are needed.

In toddlers (12-24 months), most were categorized as 'Poor' diets $(50.4 \%)$. This was not explained by an increase in the intake of sugar-sweetened beverages and unhealthy foods as seen by others [12] but again by the over consumption of foods considered healthy: milk, $100 \%$ fruit juices and protein rich foods. In particular, average consumption of milk was 26 ounces per day, which represents more than 3 bottles of 8 ounces. Although we did not systematically record it, participants reported using the milk bottle to feed the baby, adding cereals and baby foods to the milk bottle. Future studies should quantify this practice. Overconsumption of milk among infants has also been reported by others [22]. Excess milk intake could be associated with anemia and nutrient deficiencies, among other health problems [23]. In addition, a recent systematic review of 10 studies in infants concluded that high intakes of energy and protein, particularly dairy products, could be associated with higher BMI and body fatness [5].

With respect to the relative validity of the DQIS, we found a trend in the association between the score and weight status, whereas those having 'Poor' diets had a two-fold increase in the odds of Excessive weight compared to those having 'Excellent' diets. On the contrary, the score developed in the UK did not find an association between the score and BMI later in childhood [10]. Longitudinal studies are needed to evaluate if the DQIS is related to obesity later in childhood.

The findings of the present study can provide relevant information to the B-24 project. This project evaluates the evidence to support including infants and toddlers from birth to 24 months of age in the Dietary Guidelines for Americans (DGA) [24]. The main focus of the B-24 project is to revise the latest systematic reviews on important topics involving infant's nutrition and health for creating the DGA in this age group. In 
the past, this population was excluded from the DGA due to the limited information available. Today, studies have shown the importance of nutrition in this targeted population for the prevention of chronic diseases later in life $[1,4]$. The score created in the present study could be used to assess diet quality in different studies and relate this score to the development of obesity and other chronic conditions later in life, which could inform the B-24 project.

There are some limitations and strengths about the present study that should be taken into account when considering the results. One limitation of the study was related to the difficulty for some caregivers to recall the foods and beverages consumed by their infants and to estimate the portion sizes of the different foods consumed. This was in partly overcome by having a picture guide of portion sizes for the most common foods consumed by infants and toddlers. A strength of the study was that the DQIS created was based on a validated semi-quantitative FFQ specifically designed for infants and toddlers 0-24 months. This allowed taking into account amount of foods consumed, not only if the food was consumed or introduced. Anthropometric measurements and all questionnaires were completed by trained personal using standardized methods and equipment, increasing accuracy in the data obtained.

In conclusion, to our knowledge, this is the first attempt to assess diet quality in infants and toddlers considering intake of each food group and their portion sizes (for infants 8-24 months). Three DQIS were created to assess diet quality in infants and toddlers aged 0-24 months. There was a trend for a two-fold increase in Excessive weight among those with 'Poor' diets. Longitudinal studies are needed to evaluate if a low DQIS is related to obesity later in childhood in this sample and in other populations.

\section{Acknowledgements}

We thank the Puerto Rico WIC Program for their support, in particular to Dana Miró (Executive Director), Blanca Sastre (Interim supervisor of Nutrition and Lactation Division), and Marta Meaux, Nutrition Supervisor of the Trujillo Alto Clinic and her team. We also thank Mary Helen Mays from the Puerto Rico Clinical and Translational Research Consortium for her support in editing the manuscript.

This study was conducted with support from University of Puerto Rico Central Administration Grant, Capacity Advancement in Research Infrastructure, UPR-MFP 6251123 and in part by Awards 8G12MD007600 and 2U54MD007587 from the National Institute on Minority Health and Health Disparities. The content is solely the responsibility of the authors and does not necessarily represent the official views of the National Institutes of Health.

\section{Declarations}

a. Conflict of Interest: There is no conflict of interest to disclose.

b. Ethical Approval: This study was approved by the Institutional Review Board of the Medical Science Campus at the University of Puerto Rico. c. Clinical trial registration: This was an observational study. A signed consent and willingness to participate from the caregivers was obtained before the study start.

\section{References}

1. Stettler N, Stallings VA, Troxel AB, Zhao J, Schinnar R, Nelson SE, et al. Weight gain in the first week of life and overweight in adulthood: a cohort study of European American subjects fed infant formula. Circulation. 2005;111(15):1897-1903. doi:111/15/1897 [pii].

2. Rivera-Soto WT, Rodríguez-Figueroa L. Childhood obesity among Puerto Rican children: discrepancies between child's and parent's perception of weight status. Int J Environ Res Public Health. 2012;9(4):1427-1437. doi: 10.3390/ijerph9041427

3. Ogden CL, Carroll MD, Kit BK, Flegal KM. Prevalence of childhood and adult obesity in the United States, 2011-2012. JAMA. 2014;311:806814. doi:10.1001/jama.2014.732

4. Adair LS. Long-term consequences of nutrition and growth in early childhood and possible preventive interventions. Nestle Nutr Inst Workshop Ser. 2014;78:111-120. doi:10.1159/000354949

5. Pearce J, Langley-Evans SC. The types of food introduced during complementary feeding and risk of childhood obesity: a systematic review. Int J Obes (Lond) 2013;37(4):477-485. doi: 10.1038/ ijo.2013.8.

6. Briefel R, Ziegler P, Novak T, Ponza M. Feeding Infants and Toddlers Study: characteristics and usual nutrient intake of Hispanic and nonHispanic infants and toddlers. J Am Diet Assoc 2006;106(1 Supp 1):S84-95.

7. Fox MK, Pac S, Devaney B, Jankowski L. Feeding infants and toddlers study: What foods are infants and toddlers eating? J Am Diet Assoc. 2004;104(1 Supp 1):s22-30.

8. Ponza M, Devaney B, Ziegler P, Reidy K, Squatrito C. Nutrient intakes and food choices of infants and toddlers participating in WIC. J Am Diet Assoc 2004;104(1 Supp 1):s71-79.

9. Sharma S, Kolahdooz F, Butler L, Budd N, Rushovich B, Mukhina GL, et al. Assessing dietary intake among infants and toddlers 0-24 months of age in Baltimore, Maryland, USA. Nutr J. 2013;12:52. doi:10.1186/1475-2891-12-52

10. Golley R, Smithers L, Mittinty M, Brazionis L, Emmett P, Northstone $\mathrm{K}$, et al. An index measuring adherence to complementary feeding guidelines has convergent validity as a measure of infant diet quality. J Nutr. 2012;142(5):901-908. doi: 10.3945/jn.111.154971

11. Arimond M, Ruel M. Progress in developing an infant and child feeding index : IFPRI Publications. Washington, D.C. 2002.

12. Meyerkort CE, Oddy WH, O’Sullivan TA, Henderson J, Pennell CE. Early diet quality in a longitudinal study of Australian children: associations with nutrition and body mass index later in childhood and adolescence. J Dev Orig Health Dis. 2012;3(1):21-31. doi:10.1017/ S2040174411000717.

13. WIC Program. Infant Feeding Guide, A Guide for Use in the WIC and CSF Programs. Washington DC. 2009.

14.Pan American Health Organization, Organization WH. Guiding Principles for Complementary Feeding of the Breastfeed Child. Washington DC. 2001.

15. American Academy of Pediatrics. Infant - Food and Feeding n.d. (accessed December 11, 2015)

16. World Health Organization. Child Growth Standards, Training course and other tools n.d. (accessed December 11, 2015). 
17. Palacios C, Sinigaglia O, Ríos E, Santiago-Rodríguez E, Rivas-Tumanyan $\mathrm{S}$, Campos $\mathrm{M}$, et al. Validity of a semi-quantitative food frequency questionnaire (FFQ) for Hispanic infants 0-24 months. J Acad Nutr Diet. 2016. In Review

18. Food and Nutrition Service: United States Department of Agriculture. Meals and Snacks | Child and Adult Care Food Program (CACFP) n.d. (accessed December 11, 2015).

19. De Craemer M, De Decker E, De Bourdeaudhuij I, Deforche B, Vereecken $\mathrm{C}$, Duvinage $\mathrm{K}$, et al. Physical activity and beverage consumption in preschoolers: focus groups with parents and teachers. BMC Public Health 2013;13:278. doi:10.1186/1471-2458-13-278.

20. Kim H, House L. Linking consumer health perceptions to consumption of nonalcoholic beverages. Agric Resour Econ Rev. 2014;43(1):1-16.

21. Huth PJ, Fulgoni VL, Keast DR, Park K, Auestad N. Major food sources of calories, added sugars, and saturated fat and their contribution to essential nutrient intakes in the U.S. diet: data from the National Health and Nutrition Examination Survey (2003-2006). Nutr J. 2013;12:116. doi:10.1186/1475-2891-12-116.

22. Garcia MT, Granado FS, Cardoso MA. [Complementary feeding and nutritional status of 6-24-month-old children in Acrelândia, Acre State, Western Brazilian Amazon]. Cad Saude Publica. 2011;27(2):305-316.

23. Oliveira MAA, Osório MM. [Cow's milk consumption and iron deficiency anemia in children]. J Pediatr (Rio J). 2005;81(5):361-367. doi:10.2223/JPED.1386.

24. Raiten DJ, Raghavan R, Porter A, Obbagy JE, Spahn JM. Executive summary: Evaluating the evidence base to support the inclusion of infants and children from birth to 24 mo of age in the Dietary Guidelines for Americans--"the B-24 Project". Am J Clin Nutr. 2014;99(3):663S-691S. doi:10.3945/ajcn.113.072140. 